\title{
Seismic Stability Time-Frequency Analysis Method of Reinforced Retaining Wall
}

\author{
Yang Changwei, ${ }^{1}$ Zhang Shixian, ${ }^{1,2}$ Zhang Jianjing, ${ }^{1}$ and Bi Junwei ${ }^{1}$ \\ ${ }^{1}$ School of Civil Engineering, Key Laboratory of Transportation Tunnel Engineering, Ministry of Education, \\ Southwest Jiaotong University, Chengdu 610031, China \\ ${ }^{2}$ School of Civil Engineering, Panzhihua University, Panzhihua 617000, China
}

Correspondence should be addressed to Yang Changwei; 1209732335@qq.com

Received 16 April 2014; Revised 27 June 2014; Accepted 8 July 2014

Academic Editor: Kim M. Liew

Copyright (C) 2015 Yang Changwei et al. This is an open access article distributed under the Creative Commons Attribution License, which permits unrestricted use, distribution, and reproduction in any medium, provided the original work is properly cited.

\begin{abstract}
The first-order differential equation of the seismic active earth pressure is established by horizontal slices analysis method, based on the elastic wave theory, with the summarized dynamic analysis model of the reinforced retaining wall and the plane of fracture assumed as linear type. And then this paper proposes a time-frequency analysis method for the internal antiseismic stability analysis on the retaining wall. The reasonability of this method is verified by the results from other methods, for example, rule. The internal frictional angle of filling earth, the seismic intensity, and the frequency of the input earthquake wave have a predominant effect on the needed total tensile force of the lacing wires, which shows that (1) the needed total tensile force of the lacing wires goes up with the increase of the PGA and the internal frictional angle; (2) the needed total tensile force of the expandability lacing wires is bigger than that of the nonexpandability lacing wires; (3) the needed total tensile force of lacing wires is saddle distributed and the force achieves maximum value when the frequency of input wave equals the natural frequency of reinforced retaining wall. Besides, if the reinforced retaining wall is designed in compliance with the rules, the emergency capacity of reinforced retaining wall is reduced. At last, this paper not only takes into account the effect of three factors of the seismic wave (PGA, frequency, and duration) on the internal antiseismic stability analysis of reinforced retaining wall but also provides some valuable references for the time-frequency seismic design of other retaining structures.
\end{abstract}

\section{Introduction}

In Wenchuan earthquake, only one type of destruction of reinforced retaining wall caused by earthquake ground motion results in the rigid-plastic complex reinforcement's fracture. This phenomenon fully shows that reinforced retaining wall is applicable in high intensity earthquake area [1]. The earthquake stability analysis methods for reinforced retaining wall are usually pseudostatic method, limit displacement method, and numerical method [2-7]. The pseudostatic method only considers the effect of PGA on the stability of retaining wall and ignores the duration and frequency of seismic wave; while duration and frequency are not considered in limit displacement method, the method is not convenient in engineering practice with poor precision. The progress of computer techniques promotes the numerical analysis methods development in practical engineering analysis. The methods contain the finite element method, boundary element method, the meshless method, and so forth $[8,9]$. Among those analysis methods, the meshless method is suitable in resolving practical problems, and another problem as mesh distortion in the finite element method and boundary element method can be generally avoided. Now, there are dozens of meshless methods, and each method uses different weighted residuals and approximate functions [10], which might be the direction of development in numerical analysis methods. As for the design of the reinforced retaining wall, results are more precise than pseudostatic method, finite element method, and boundary element method. It can consider the effect of PGA likewise, duration, and frequency of seismic wave, and nonlinear behavior of backfill earth on the stability of retaining wall. However, the meshless method 
is hard for the engineers to learn and implement. Results of study also indicate that duration and frequency of seismic wave have remarkable effect on the earthquake stability of reinforced retaining wall $[11,12]$. It is thus important to strengthen time-frequency analysis method on the stability of reinforced retaining wall under earthquake excitation, which can be easily used in reinforced earth wall design and solves the problem of general design methods unable to consider the effect of frequency and duration of seismic wave. For example, this method is compatible in EXCEL or other simple procedures (see Figure 1).

According to the reports on retaining walls damage in the Wenchuan earthquake $[13,14]$, the SV-wave of which vibrating direction is perpendicular to the direction of propagation in the cross-section of retaining wall is the most destructive wave. Moreover, SV-wave is a complex nonstationary signal and its frequency alters gradually over time, restricting the practical usage of pseudostatic method and limited displacement method. To tackle the problem, this paper presents an analysis work based on the elastic wave theory [15] and summarizes the dynamic analysis model of reinforced retaining wall. For the case of expandability and nonexpandability lacing wires, the plane of the fracture being linear type is assumed and thus the first-order differential equation of the seismic active earth pressure is established by horizontal slices analysis method. After that, by use of Hilbert-Huang transform method [16], authors have proposed a time-frequency analysis method for internal antiseismic stability analysis of reinforced retaining wall under SV-wave excitation. The validation of the new method is illustrated and verified through shaking table test and numerical analysis. In an effort to study the advantages of the method, the seismic stability calculation of reinforced retaining wall is conducted and further compared with the relevant results from time-frequency analysis method, pseudostatic method, and numerical simulation method.

\section{Time-Frequency Analysis Method of the Antiseismic Stability for Reinforced Retaining Wall}

According to the above shortcomings of pseudostatic method and limited displacement method, this paper proposes a time-frequency analysis method, which can take fully into account the effect of three elements of the seismic wave on the antiseismic stability of reinforced retaining wall. Its derived process follows this train of thought: firstly, summarize the analysis model. The sliding mass of retaining wall is divided into several horizontal slices by slices method. Solve the force induced by seismic wave at infinitesimal body of any layer based on HHT and elastic wave theory, and then one can establish a mechanical balance equation of microelement. By such analogy, the governing equations of the whole sliding mass are deduced. Hence, the needed total tensile force and length of the lacing wires for the reinforced retaining wall are worked out. In essence, the inertial force is a simplified quantification [17] of seismic wave's propagation in the soil.

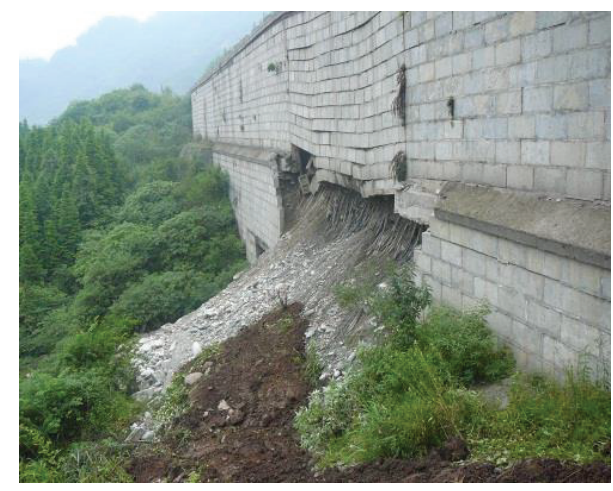

FIGURE 1: Failure of reinforced retaining wall in Wenchuan earthquake.

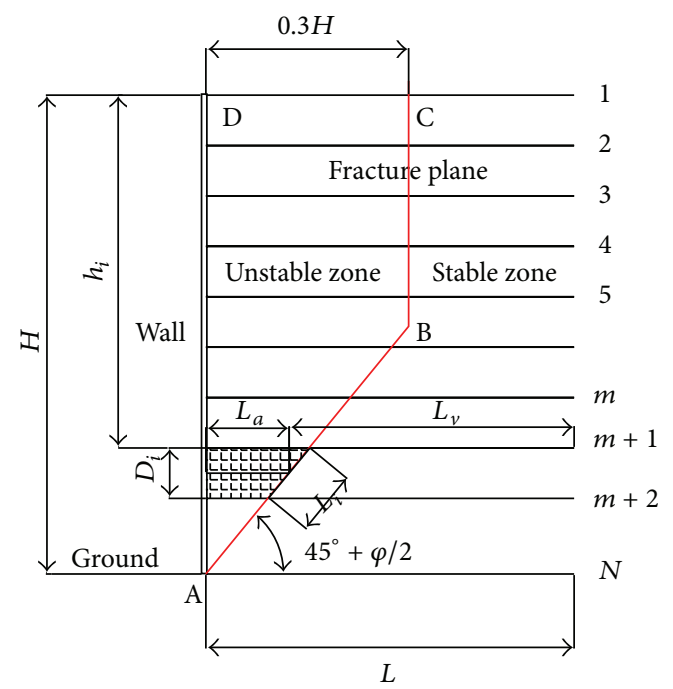

Figure 2: Nonductility reinforcement.

Therefore, the horizontal seismic inertial force should be equivalent to the wave force in this paper.

\subsection{Formula Derivation of Time-Frequency Analysis Method}

2.1.1. Basic Assumptions. The time-frequency analysis method of the antiseismic stability for reinforced retaining wall depends on the following assumptions. (1) The location and shape of rupture planes in the backfill soil behind the retaining wall are very important to determine the crosssection and length of rods. In the specifications for design of highway reinforced earth engineering $[18,19]$, there are two kinds of simplified rupture planes for the geosynthetics with different modulus, and the rupture planes are shown in Figures 2 and 3. The first simplified rupture plane is linear type plane where dip angle is $45^{\circ}+\Phi / 2$. This plane can divide the backfill soil into two sections, including active zone and passive zone. If the reinforcement is ductile, a number of field test results indicate that this rupture plane is close to the real failure plane. The second rupture plane is bend linear type plane, divided into two sections, which contains vertical section and inclined section. In the vertical section, the height is $h_{1}=H / 2$ and the distance from the retaining wall is $b$. 


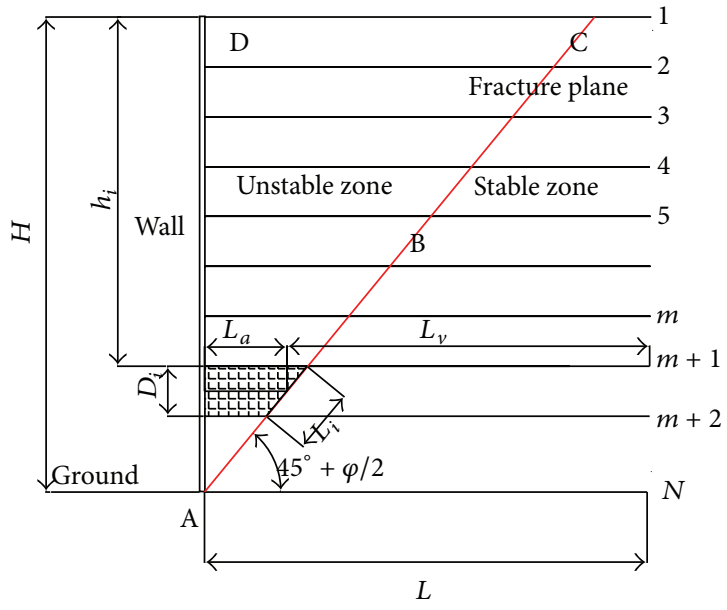

FIgURE 3: Reinforcement with ductility.

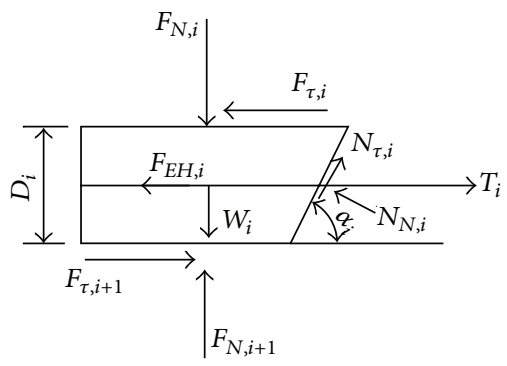

Figure 4: Analysis model of horizontal soil layer.

In the inclined section, the height is $h_{2}=H / 2$ and the dip angle is $45^{\circ}+\Phi / 2$. If the reinforcement is nonductile, field test results show that this rupture plane is close to the real failure plane. Therefore, according to the characteristics of rods, this paper simplifies the rupture plane to two kinds. (2) In the real reinforced earth retaining wall engineering, the backfill soil is placed in layers, while not every layer is proper continuous, homogeneous, and isotropic. As a theoretical study, this paper assumes that the backfill soil meets the above characteristics. A number of research results indicate that the above assumptions of backfill soil cannot produce bigger effect on the calculated results. (3) When the seismic wave spreads from the bottom of the retaining wall to the top, the internal material damping will dissipate major seismic energy, the seismic wave will produce waveform transformation, and the seismic wave will be transformed into surface wave, behaving in the elliptical polarization movement. The reflective seismic wave on the upper surface of soil carries a small amount of energy of downpropagation, which has been verified by the same results. In this paper, ignoring the influence of surface reflective seismic wave is reasonable.

2.1.2. Generalized Model. For the cases of expandable and nonexpandable lacing wires, one can establish mechanical balance equations of the selective microelement by horizontal slice method, respectively. Figure 4 shows the parameters of unit-volume selected out as follows: the self-weight of

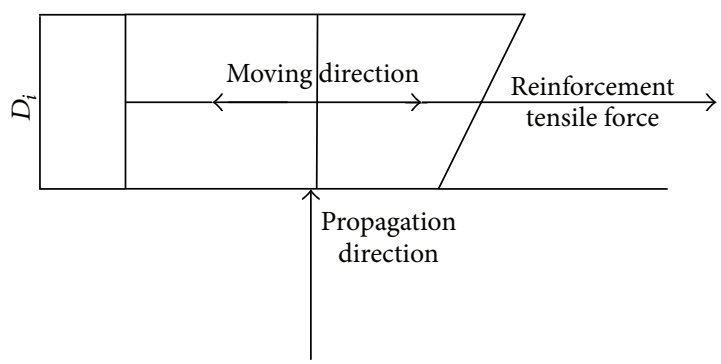

FIGURE 5: Wave-force model of horizontal soil layer.

the slice is $W_{i}$; the normal and shear interaction forces of the upper individual horizontal slice are $F_{N, i}, F_{t, i}$, respectively, and those of the lower slice are $F_{N, i-1}, F_{t, i-1}$; tensile force of the geosynthetic at layer $i$ is $T_{i}$; the horizontal inertial force on the slice is $F_{E H, i}$; the angle between rupture plane and horizontal plane is $\alpha_{i}$. The free-body diagram of wave force on the horizontal slice is shown in Figure 5.

2.1.3. Calculated Tension of Reinforcement. In Figure 4, when the force of slice $i$ reached a balance, the total of all vertical components is zero:

$$
\begin{gathered}
F_{N, i+1}-F_{N, i}-W_{i}+N_{t, i} \sin \alpha_{i}+N_{N, i} \cos \alpha_{i}=0, \\
N_{t, i}=c l_{i}+N_{N, i} \tan \phi,
\end{gathered}
$$

where $c$ is the cohesion of the filling earth and $\varphi$ is the internal frictional angle.

Bring (2) into (3); the normal force of the horizontal slice $F_{N, i}$ can be derived:

$$
N_{N, i}=\frac{F_{N, i}-F_{N, i+1}+W_{i}-c l_{i} \sin \alpha_{i}}{\tan \varphi \sin \alpha_{i}+\cos \alpha_{i}} .
$$

When the whole sliding mass reached a balance, the sum of all horizontal components is zero:

$$
\sum_{i=1}^{n} T_{i}+\sum_{i=1}^{n} N_{t \cdot i} \cos \alpha_{i}-\sum_{i=1}^{n} N_{t \cdot i} \sin \alpha_{i}-\sum_{i=1}^{n} F_{E H, i}=0 .
$$

Bringing (2) and (3) into (4), we can get that

$$
\begin{aligned}
\sum_{i=1}^{n} T_{i} & +\sum_{i=1}^{n}\left(c l_{i}+N_{N, i} \tan \phi\right) \cos \alpha_{i} \\
& -\sum_{i=1}^{n} \frac{F_{N, i}-F_{N, i+1}+W_{i}-c l_{i} \sin \alpha_{i}}{\tan \varphi \sin \alpha_{i}+\cos \alpha_{i}} \sin \alpha_{i} \\
& -\sum_{i=1}^{n} F_{E H, i}=0 .
\end{aligned}
$$

The potential function of SV-wave can be formulated uniformly by elastic displacements [20], as follows:

$$
u(z, t)=U(z) e^{i \omega t},
$$


where $U(z, t)$ is the displacement function of microunit $i$; $U(z)$ is the amplitude of the elastic displacement of microunit $i$; $\omega$ is the vibrational frequency of microunit $i$.

Then, the inertial force which is generated by SV-wave of microunit $i$ is as follows:

$$
F_{E H, i}=\left|w_{i} \cdot \frac{\partial^{2} u / \partial t^{2}}{g}\right|=\frac{W_{i} w^{2} U(z)}{g} .
$$

Hence, the needed total tensile force of the expandability and nonexpandability lacing wires in reinforced retaining wall can be obtained, respectively, by bringing (7) into (5), as follows:

$$
\begin{aligned}
\sum_{i=1}^{n} T_{i}= & \rho V w^{2} U(z)-\frac{c H \cos \alpha}{\sin \alpha} \\
& -\frac{[\cos \alpha \tan \varphi-\sin \alpha]\left[F_{N, 0}+W-c H\right]}{\tan \varphi \sin \alpha+\cos \alpha}, \\
\sum_{i=1}^{n} T_{i}= & \rho V w^{2} U(z)-0.3 c H \\
& +\frac{0.3(1-0.3 \tan \alpha) \gamma H^{2}-[c(1-0.3 \tan \alpha) H]}{\tan \varphi} \\
& \times\left([\cos \alpha \tan \varphi-\sin \alpha]\left[F_{N, 0}+0.045 \gamma H^{2} \tan \alpha\right]\right. \\
& \times(\tan \varphi \sin \alpha+\cos \alpha)^{-1},
\end{aligned}
$$

where $F_{N, 0}$ is the overload at the top surface of the retaining wall; $\omega$ is the instantaneous frequency of SV-wave, which changes over time; $\rho$ is the density of the filling earth behind retaining wall; $V$ is the volume of the sliding mass $\mathrm{ABCD} ; \alpha$ is the angle between the rupture plane inclined part of retaining wall and the horizontal plane.

The needed total tensile force $\left(\sum_{i=1} T_{i}\right)$ of the lacing wires in reinforced retaining wall can be transformed into the dimensionless value $K$, which is equal to the coefficient of soil pressure with the traditional design method for retaining wall. And then the formulation of $K$ is that

$$
K=\sum_{i=1}^{n} \frac{T_{i}}{\gamma H^{2}}
$$

The tensile force of lacing wires at layer $i$ is $T_{i}$, as follows:

$$
T_{i}=\gamma h_{i} D_{i} K
$$

2.2. Analysis Mentality of Time-Frequency Effect. Timefrequency effect of seismic wave is mainly manifested in the elastic amplitude $U(z)$ and frequency $\omega$ of input seismic excitation. The analysis procedures of time-frequency effect proposed in this paper are as follows. (1) Decompose the seismic wave to several intrinsic mode functions (IMF)

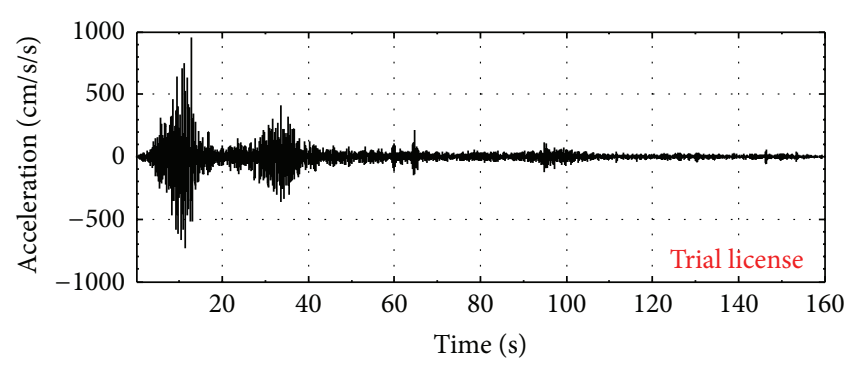

Figure 6: Time history of Wenchuan-Wolong wave.

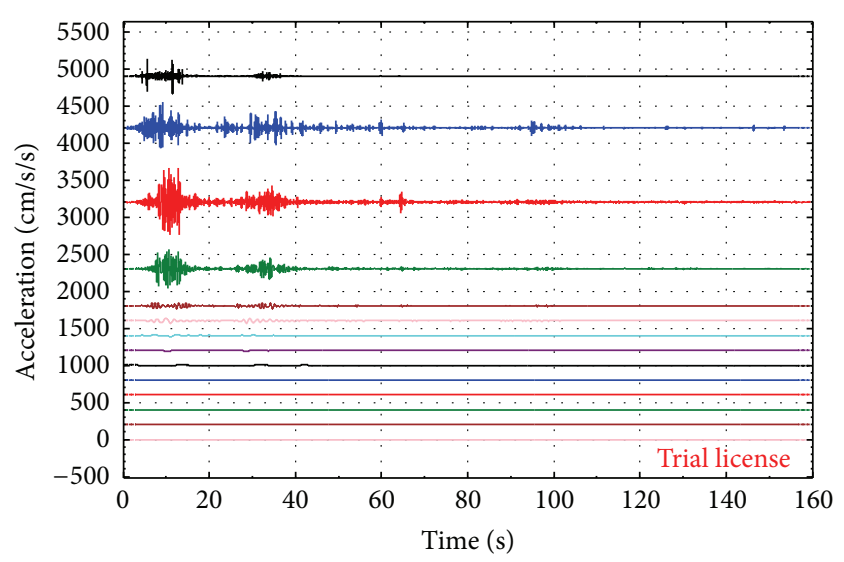

FIgURE 7: Acceleration time history of IMF.

by the empirical mode decomposition (EMD) method. (2) Convert the multiple-channel multiple signals which consist of IMF to several single-channel single signals by conducting channel switch. (3) Solve instant frequency of each channel and plot the frequency time history curve. (4) The needed total tensile force of lacing wires can be obtained by bringing every IMF and its instant frequency into (8) and (9).

From the above analysis, we know that time-frequency effect method of the antiseismic stability of reinforced retaining wall proposed in this paper can offset the drawbacks of pseudostatic method and limited displacement method. Moreover, it considers the effects of PGA, frequency, and duration primly for the stability of reinforced retaining wall under earthquake.

2.3. Application of Time-Frequency Effect for Seismic Wave. In order to illustrate the application of time-frequency effect for seismic wave particularly, authors chose Wolong seismic waves input to carry out time-frequency analysis. (1) Input the Wolong seismic wave (Figure 6). (2) Disintegrate the seismic wave into multiple IMF by conducting EEMD method (Figure 7). (3) Solve the instant frequency of each IMF (Figure 8).

Note that owing to sustenance over long periods of time for Wolong seismic wave, in Figures 7 and 8, the time history is only chosen from zero to eighty seconds, including peak ground acceleration. 
TABLE 1: Comparison of tensile force of reinforcement between time-frequency and other calculated methods.

\begin{tabular}{|c|c|c|c|c|c|c|c|c|c|}
\hline \multirow{3}{*}{ PGA } & \multicolumn{3}{|c|}{ Tensile force $(\mathrm{kN})$} & \multicolumn{3}{|c|}{ Tensile force $(\mathrm{kN})$} & \multicolumn{3}{|c|}{ Tensile force $(\mathrm{kN})$} \\
\hline & & $\varphi=20^{\circ}$ & & & $\varphi=25^{\circ}$ & & & $\varphi=30^{\circ}$ & \\
\hline & $T-F$ & Shahgholi et al. [21] & Code & $T-F$ & Shahgholi et al. [21] & Code & $T-F$ & Shahgholi et al. [21] & Code \\
\hline 0.1 & 151 & 159 & 156 & 137 & 147 & 144 & 123 & 118 & 117 \\
\hline 0.2 & 161 & 171 & 169 & 146 & 157 & 154 & 145 & 138 & 136 \\
\hline 0.4 & 177 & 189 & 184 & 161 & 173 & 169 & 157 & 150 & 145 \\
\hline
\end{tabular}

Note: PGA means peak ground acceleration; $T-F$ means time-frequency method presented in this paper; Sha means method presented by Shahgholi et al., $2001[21]$.

TABLE 2: Error analysis of tensile force of reinforcement between time-frequency and other calculated methods.

\begin{tabular}{|c|c|c|c|c|c|c|}
\hline \multirow{3}{*}{ PGA } & \multicolumn{2}{|c|}{ Tensile force (\%) } & \multicolumn{2}{|c|}{ Tensile force (\%) } & \multicolumn{2}{|c|}{ Tensile force (\%) } \\
\hline & \multicolumn{2}{|c|}{$\varphi=20^{\circ}$} & \multicolumn{2}{|c|}{$\varphi=25^{\circ}$} & \multicolumn{2}{|c|}{$\varphi=30^{\circ}$} \\
\hline & Shahgholi et al. [21] & Code & Shahgholi et al. [21] & Code & Shahgholi et al. [21] & Code \\
\hline 0.1 & 5.30 & 3.14 & 7.30 & 4.76 & -4.07 & -5.08 \\
\hline 0.2 & 6.21 & 4.68 & 7.53 & 5.10 & -4.83 & -6.52 \\
\hline 0.4 & 6.78 & 3.70 & 7.45 & 4.62 & -4.46 & -8.00 \\
\hline
\end{tabular}

Note: error $=$ (the results of Shahgholi et al. [21] or Code-that of $T-F) * 100 \% /$ the results of $T$-F.

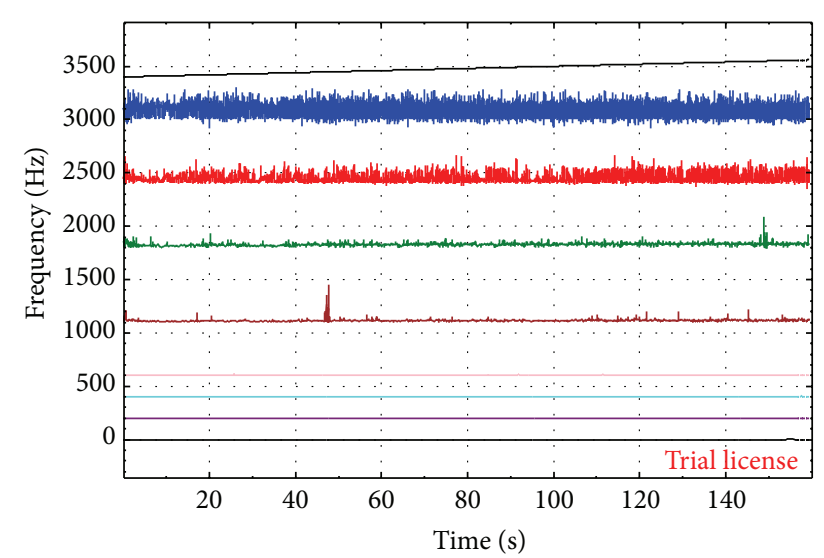

FIGURE 8: Frequency time history of IMF.

\section{Solution Procedures of Time-Frequency Analysis Method for the Antiseismic Stability of Reinforced Retaining Wall}

The solution procedures of time-frequency analysis method for the antiseismic stability of reinforced retaining wall proposed in this paper are as follows.

(1) Summarize the analysis model, based on the panel, filling earth, geosynthetics of reinforced retaining wall, and actual site condition.

(2) Judge the place of fracture plane and bar spacing in accordance with the physical characteristic of soil and the type of reinforcement.

(3) Determine the design response spectra according to the "Code for Seismic Design of Buildings," and then synthesize the acceleration time history by the method detailed in [22].
(4) Generate displacement time history curve according to acceleration time history curve; then, with HilbertHuang transform, solve all the intrinsic mode functions of seismic wave and corresponding frequency time history curves.

(5) Bring the results above into (8) or (9) to obtain the needed total tensile force of the lacing wires; moreover, in alliance with (10), acquire the tension of reinforcement in each layer.

(6) Based on the above calculations and the position of rupture plane, we can get the requisite sectional area and the length of any reinforcement.

\section{Verification of Time-Frequency Analysis Method for the Antiseismic Stability of Reinforced Retaining Wall}

In order to verify the correctness of time-frequency analysis method for the antiseismic stability of reinforced retaining wall, we consider the effect of the PGA, however, regardless of the frequency of seismic wave. For example, the unit weight of the backfill is $20 \mathrm{kN} / \mathrm{m}^{3}$ and the height of retaining wall is $5 \mathrm{~m}$, to arrange 18 layers of expandability lacing wires with constant spacing, and the antipull friction coefficient is 0.75 ; characteristic values of the shear strength parameters for the backfill are $c=0$ and $\varphi=20^{\circ}, 25^{\circ}, 30^{\circ}$, respectively, PGA of the input sinusoidal wave is $0.1,0.2,0.4(\mathrm{~g})$, and the frequency is $15 \mathrm{HZ}$ which is beyond the incidence of frequency about seismic wave by part 3 . The results of the total tensile force are shown in Tables 1 and 2.

In general, the maximum error is $8.0 \%$, and the minimum error is $3.14 \%$, which can show that the results by timefrequency analysis method when ignoring the effect of frequency which are shown in Tables 1 and 2 are consistent with that by the current standard method and reference. 


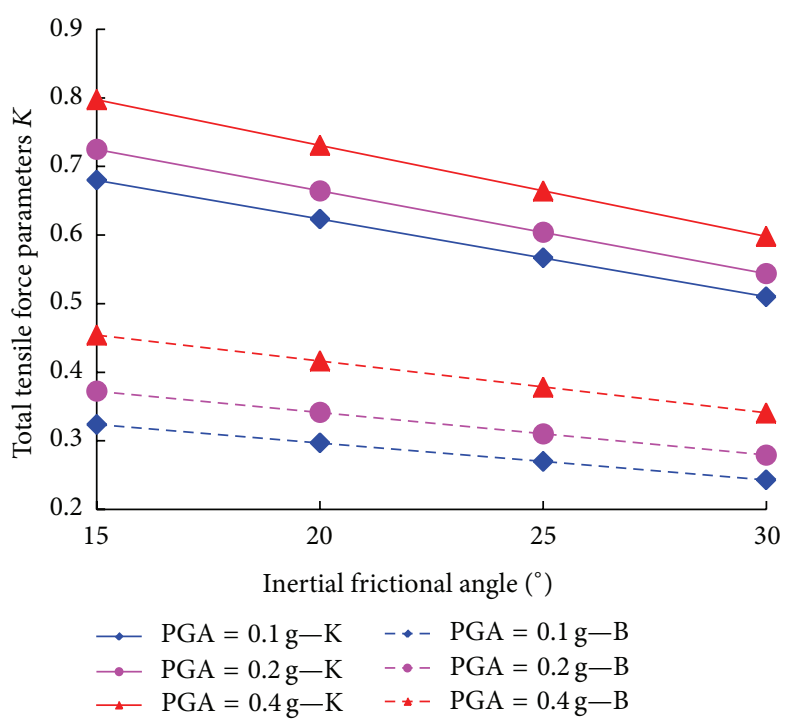

FIGURE 9: Relationship between total tensile force parameter $K$ and internal friction angle of fill under frequency of $0.2 \mathrm{~Hz}$.

Hence, the comparing simulation results proves the reliability and effectiveness of the new method proposed in this paper.

\section{Parametric Study of Time-Frequency Analysis Method for the Antiseismic Stability of Reinforced Retaining Wall}

For the time-frequency analysis method of reinforced retaining wall, the internal frictional angle of the filling earth, the seismic intensity, and the frequency of the input earthquake wave in different types of geosynthetics have a predominant effect on the parameter $K$. For example, the unit weight of the backfill is $20 \mathrm{kN} / \mathrm{m}^{3}$ and the height of retaining wall is $5 \mathrm{~m}$; arrange 18 layers of reinforcements with a constant spacing and the antipull friction coefficient is 0.75 ; characteristic values of the shear strength parameters for the backfill are $c=0$ and $\varphi=15^{\circ}, 20^{\circ}, 25^{\circ}, 30^{\circ}$, respectively, and PGA of the input sinusoidal wave is $0.1,0.2,0.4(\mathrm{~g})$ with the frequency change among $0.1,0.2,0.4,0.8,1.0,2,4,5,6,8$, and $10(\mathrm{HZ})$.

The values of the parameter $K$ are shown in Figures 9, 10, 11 , and 12 , and as well $K$ and $B$ represent the expandable and nonexpandable lacing wires separately.

Analyzing Figure 9 to Figure 12 comprehensively, we can reach that the parameter $K$ of the total tensile force of the lacing wires decreases with the increase of the internal frictional angle, and it may be because of the following reasons: the frictional resistance on the surface of lacing wires increases with the frictional angle, which improves the pulling resistance of lacing wires, and then the total tensile force reduces. However, the inertia force of backfill earth increases with the increase of the PGA, and then the total tensile force of lacing wires also increases significantly; the parameter $K$ of the total tensile force of the expandability lacing wires is bigger than that of the nonexpandability lacing wires, and it may be because of the following reasons: if

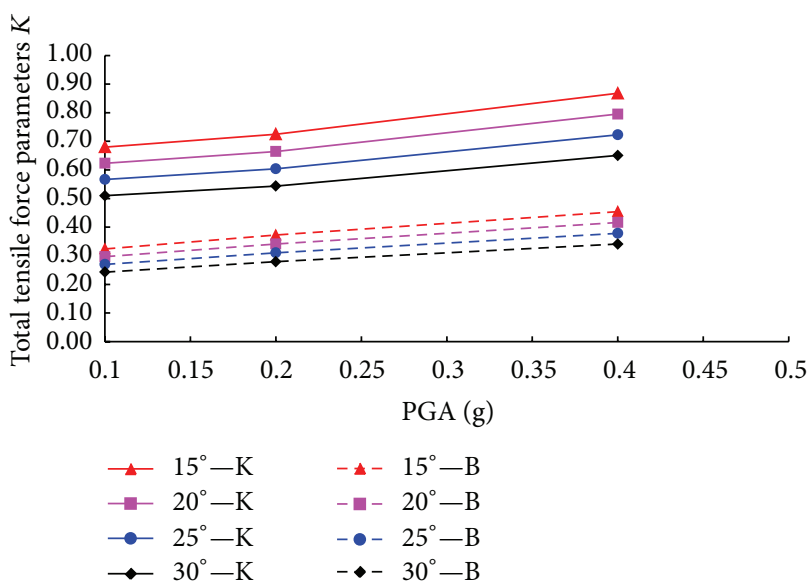

FIGURE 10: Relationship between total tensile force parameter $K$ and PGA under frequency of $0.2 \mathrm{~Hz}$.

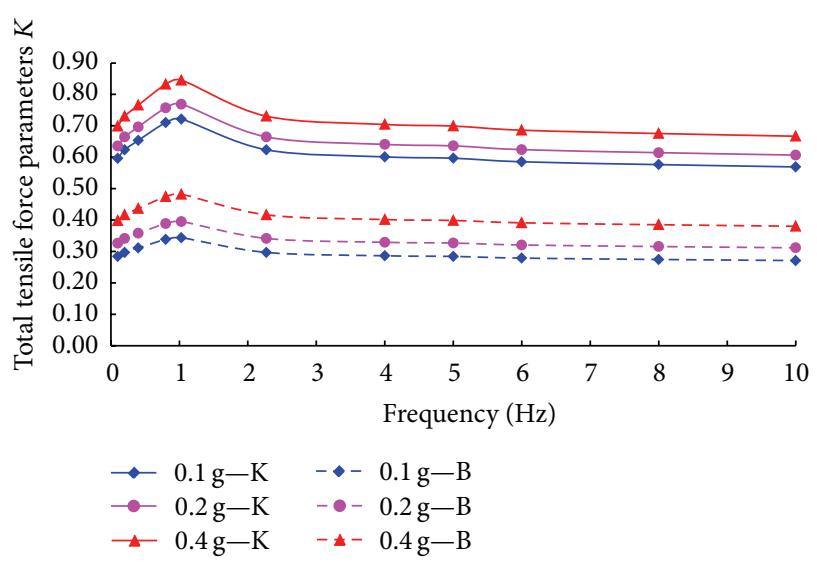

FIGURE 11: Relationship between total tensile force parameter $K$ and frequency under internal friction angle of 20 degrees.

the reinforcement is ductility, the rupture plane is linear. On the contrary, the rupture is bending rupture plane that the reinforcement is nonductility. However, the wedge formed by the linear type plane is bigger than that formed by the bend linear type plane, and then the inertia force of the former is bigger than the latter, so the parameter $K$ of the total tensile force of the expandability lacing wires is bigger than that of the nonexpandability lacing wires; the needed total tensile force of lacing wires is distributed in the shape of saddle and the force achieves the maximum value when the frequency of the input wave is $1 \mathrm{HZ}$. This phenomenon is because the instant frequency $(1 \mathrm{HZ})$ of the input seismic wave is close to the natural frequency $(1.16 \mathrm{HZ})$ of the retaining wall, causing the resonance effect to be enhanced; for the expandability and nonexpandability lacing wires, the calculations of $K$ with the method that is proposed in this paper range from 1.0 to 1.25 , while that value with normative methodologies between 1.02 and 1.35 (both inclusive), which indicate seismic safety reserve of retaining wall, may be lowered by formal methods for the design of antiseismic stability of the reinforcement retaining wall. 


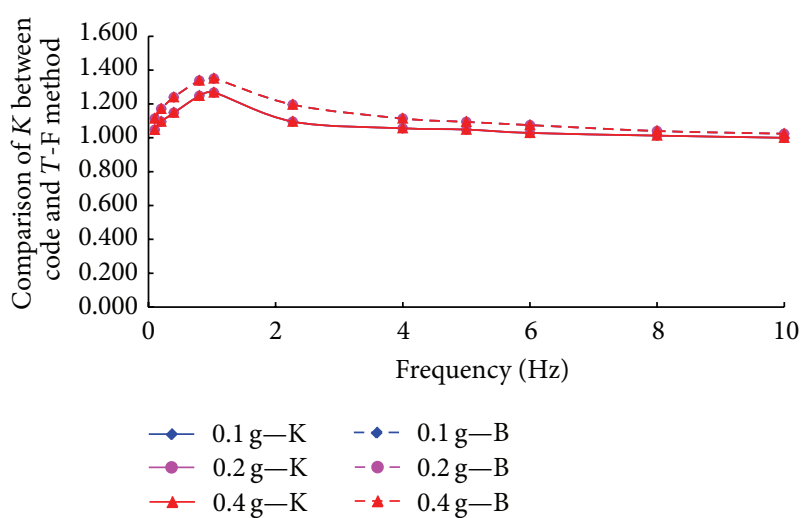

FIGURE 12: Relationship between different total tensile force parameter $K$ and frequency under internal friction angle of 20 degrees.

From the above analysis, one can know that the type of geosynthetic, the internal frictional angle of the filling earth, the seismic intensity, and the frequency of the input earthquake wave have a predominant effect on the antiseismic stability of the reinforced retaining wall. Therefore, the effect of the above factors should be given due considerations in the earthquake-resistant design.

\section{Conclusions}

Based on the above analysis, the following conclusions can be concluded.

First, for the expandability and nonexpandability lacing wires, based on the elastic wave theory, we summarize the dynamic analysis model of the reinforced retaining wall and establish time-frequency analysis method of the antiseismic stability with HHT method by horizontal slices analysis method. And then the reasonability of this method is verified by the results of the other methods, for example, normative methodologies. The new method not only considers the effect of three factors of the seismic wave (PGA, frequency, and duration) on the internal antiseismic stability analysis of reinforced retaining wall and improves the seismic design accuracy greatly but also provides some valuable references for the seismic design of the other retaining structures.

Second, the type of geosynthetic, the internal frictional angle of the filling earth, the seismic intensity, and the frequency of the input earthquake wave have a predominant effect on the antiseismic stability of the reinforced retaining wall, which should be given due considerations in the earthquake-resistant design. Likewise, for the expandability and nonexpandability lacing wires, seismic safety reserve of retaining wall may be lowered by formal methods for the design of antiseismic stability of the reinforcement retaining wall when considering the effect of the PGA, while ignoring the frequency.

Third, the needed total tensile force of the lacing wires decreases with the increase of the internal frictional angle; on the contrary, it increases significantly with the increase of the PGA; the total tensile force of the expandability lacing wires is bigger than that of the nonexpandability lacing wires, and it is distributed in the shape of saddle and the force achieves the maximum value when the frequency of the input wave is the same as the natural frequency of reinforced retaining wall.

\section{Conflict of Interests}

The authors of this paper do not have any conflict of interests regarding the publication of this paper.

\section{Acknowledgments}

This study is supported in part by NSF of China (Contract no. 51408510), Construction and Science and Technology Project of Ministry of Transport (2013 318800 020), Guangxi Science Foundation, the Program for Science and Technology of Henan Province in China (Grant no. 142300410200), and Science Foundation of Key Laboratory of High-speed Railway Engineering, Ministry of Education, School of Civil Engineering, Southwest Jiaotong University (Grant no. 2014HRE-05).

\section{References}

[1] L. haiguang and Z. Depei, Design of the New Retaining Structure and Engineering Practice, Monographs, Communications Press, Beijing, China, 2004.

[2] J. Jianqing, "Interior stability analysis of reinforced earth retaining wall under complicated dynamical loads," Central South Highway Engineering, vol. 32, no. 1, pp. 51-54, 2007.

[3] J. Yingchun, "Internal stability calculation of reinforced retaining wall subjected to seismic load," Chinese Journal of Highway, vol. 10, no. 5, pp. 43-47, 1991.

[4] H. B. Liu, "Internal stability analysis of segmental geosyntheticreinforced soil retaining walls subjected to seismic loading," Chinese Journal of Geotechnical Engineering, vol. 30, no. 2, pp. 278-279, 2008.

[5] M. M. El-Emam, Behaviour of reinforced soil walls under earthquake loading [Ph.D. thesis], Queen's University of Canada, Kingston, Canada, 2003.

[6] Y. Youhai, "Stability analysis on the reinforced earth retaining wall under earthquake loadings," Journal of Lanzhou Railway University, vol. 21, no. 4, pp. 9-11, 2007.

[7] P. Cui, Y.-Y. Zhu, Y.-S. Han, X.-Q. Chen, and J.-Q. Zhuang, "The 12 May Wenchuan earthquake-induced landslide lakes: distribution and preliminary risk evaluation," Landslides, vol. 6, no. 3, pp. 209-223, 2009.

[8] L. W. Zhang, Z. X. Lei, K. M. Liew, and J. L. Yu, "Static and dynamic of carbon nanotube reinforced functionally graded cylindrical panels," Composite Structures, vol. 232, no. 111, pp. 205-212, 2014.

[9] L. W. Zhang, P. Zhu, and K. M. Liew, “Thermal buckling of functionally graded plates using a local Kriging meshless method," Composite Structures, vol. 108, pp. 472-492, 2014.

[10] X. Zhang, X.-H. Liu, K.-Z. Song, and M.-W. Lu, "Leastsquares collocation meshless method," International Journal for Numerical Methods in Engineering, vol. 51, no. 9, pp. 1089-1100, 2001.

[11] C. B. Burke, Full-scale shaking table tests and finite element analysis of reinforced soil retaining walls [Ph.D. thesis], Columbia University, New York, NY, USA, 2004. 
[12] Y. Shengming, "Experimental study on reinforced soil retaining wall and analysis of deformation mechanism," in Monographs, pp. 9-11, Dalian University of Technology Press, Dalian, China, 2009.

[13] C. Hua, The experimental study on mechanical characteristics of geogrid-reinforced soil retaining wall [Ph.D. thesis], China Academy of Railway Sciences, 2011.

[14] J. Liang, Seismic response and dynamic stability analysis of reinforced retaining wall [Ph.D. thesis], Lanzhou University of Technology, Lanzhou, China, 2011.

[15] X. Du, Theories and Methods of Wave Motion for Engineering, Science Press, Beijing, China, 2009.

[16] N. E. Huang, Z. Shen, S. R. Long et al., "The empirical mode decomposition and the Hilbert spectrum for nonlinear and non-stationary time series analysis," The Royal Society of London A, vol. 454, no. 1971, pp. 903-995, 1998.

[17] C. Yang, J. Zhang, and D. Zhou, "Research on time-frequency analysis method for seismic stability of rock slope subjected to SV wave," Chinese Journal of Rock Mechanics and Engineering, vol. 32, no. 3, pp. 483-491, 2013.

[18] Ministry of Transport of the People's Republic of China, JTJ015-91 Specifications for Design of Highway Reinforced Earth Engineering, Standard, China Communications Press, Beijing, China, 1999.

[19] U. S. Department of Transportation and Federal Highway Administration, FHWA2N HI2002043 Mechanically Stabilized Earth Walls and Reinforced Soil Slopes Design \& Construction Guidelines, Standard, National Highway Institute Office of Bridge Technology, Washington, D.C., USA, 2002.

[20] D. Xiuli, Theories and Methods of Wave Motion for Engineering, Monographs; Science Press, Beijing, China, 2008.

[21] M. Shahgholi, A. Fakher, and C. J. F. P. Jones, "Horizontal slice method of analysis," Geotechnique, vol. 51, no. 10, pp. 881-885, 2001.

[22] H. Yuxian and X. Xun, "Phase angle consideration in generating response spectrum-compatible ground motion," Earthquake Engineering \& Engineering Vibration, vol. 6, no. 2, pp. 37-51, 1986. 


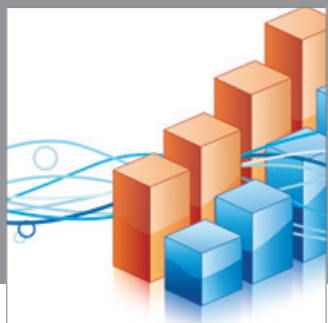

Advances in

Operations Research

mansans

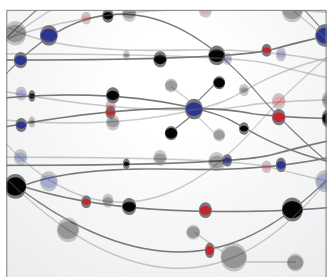

The Scientific World Journal
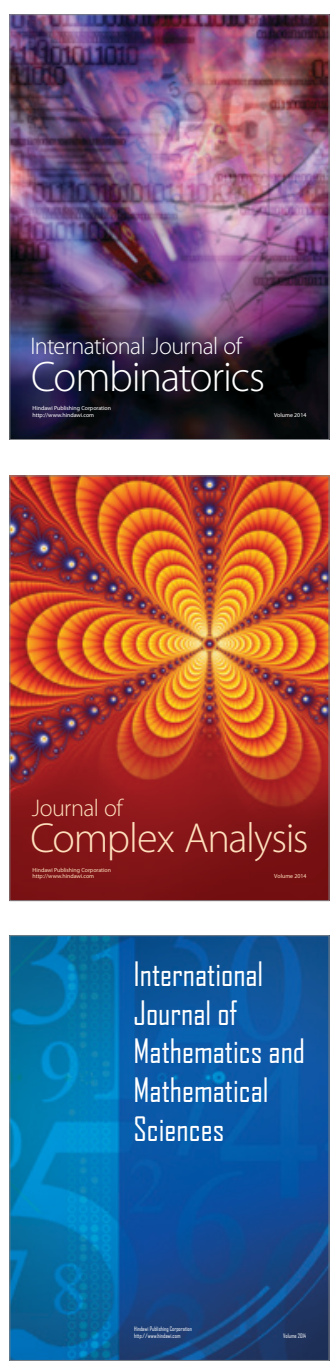
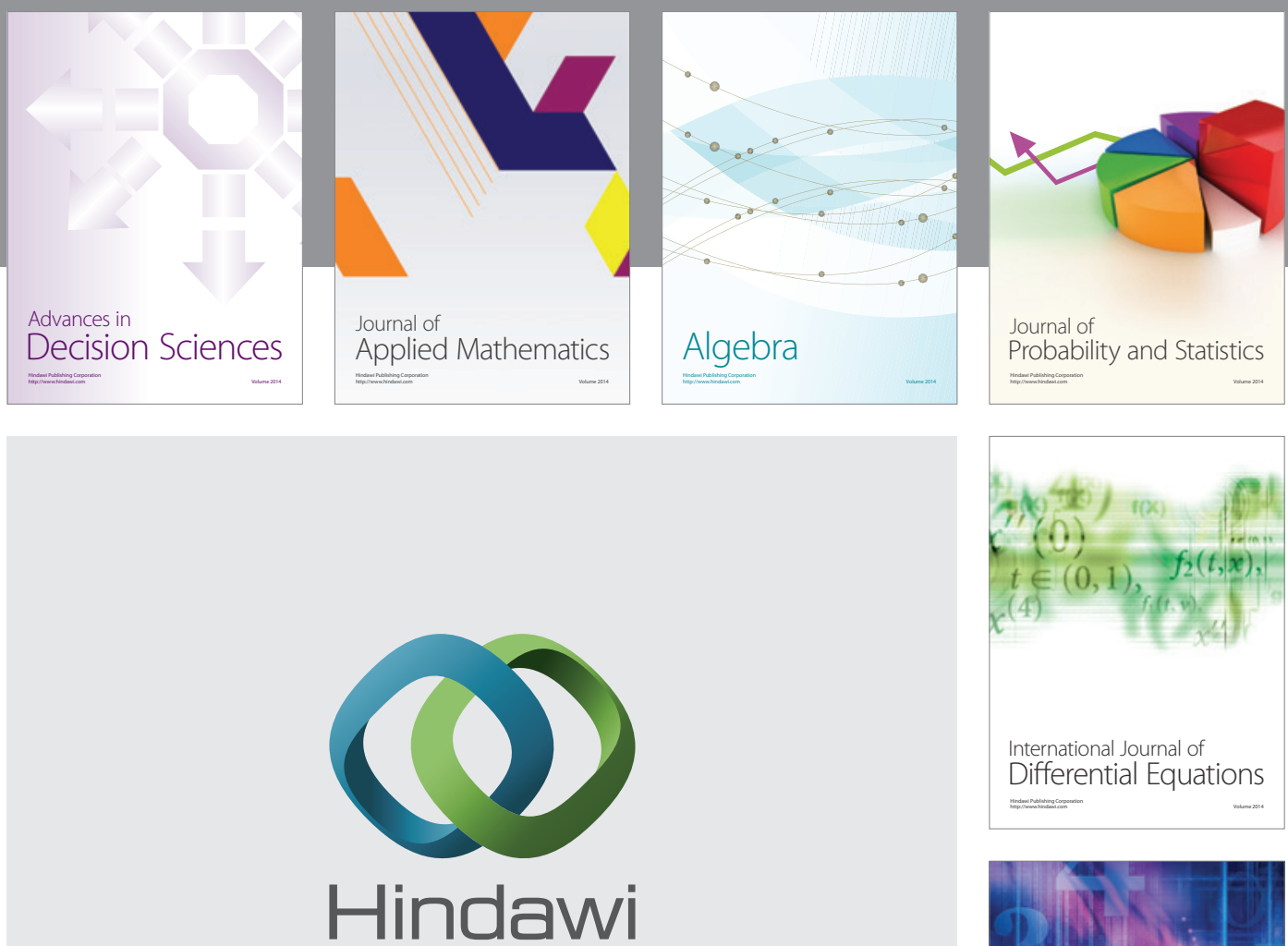

Submit your manuscripts at http://www.hindawi.com
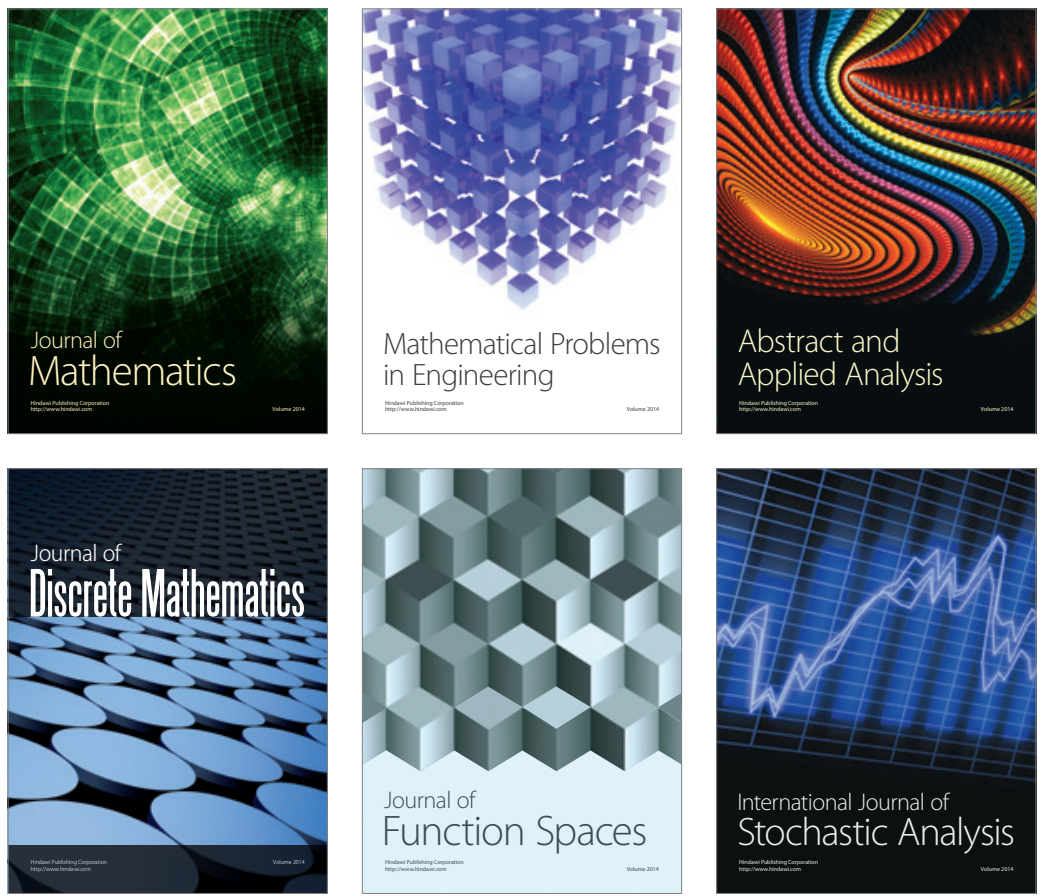

Journal of

Function Spaces

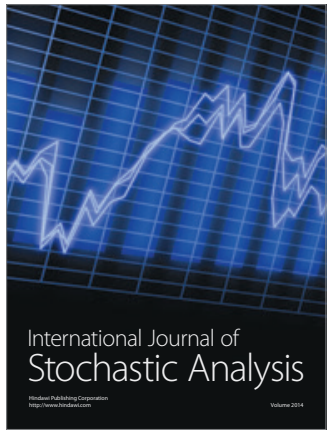

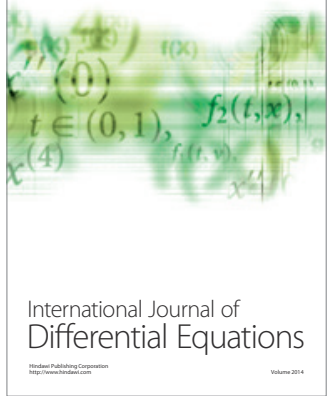
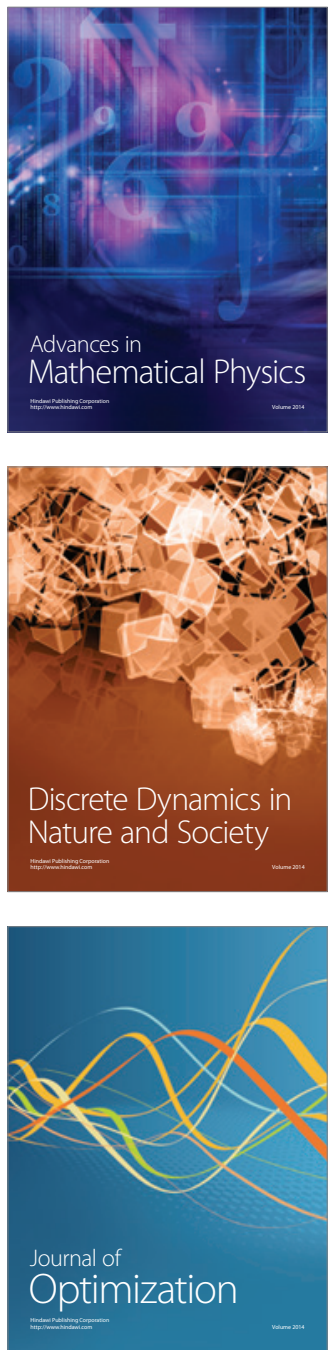